\title{
Parametric Optimization of Butt Welded Polycarbonate using Response Surface Methodology
}

\author{
Abid Imtiaz ${ }^{1 a}$, Adnan Tariq ${ }^{1 b}$, Ajaz Bashir Janjua ${ }^{1 c}$, Fahad Sarfraz ${ }^{2}$, \\ Amar ul Hassan Khawaja ${ }^{3}$
}

RECEIVED ON 23.05.2019, ACCEPTED ON 03.03.2020

\begin{abstract}
Friction Stir Welding (FSW) is a solid-state joining process for metals, non-metals and polymers. It is carried out with the help of a specially designed, non-consumable tool. The heat required, for creating a softened region at the faying surfaces, is generated by rotation of tool against the work piece material. Being a solid-state welding process, it offers several advantages like inducing minimum effect on the mechanical properties of base material, reduced shrinkage and distortion, no spatter or Ultra Violet (UV) radiations etc. However, developing a sound weld requires an appropriate combination of several process parameters $e$.g. the design of tool, its rotational and traversing speeds etc. To substantiate this aspect, an approach based on Response Surface Methodology (RSM) is presented during this paper that optimizes the combination of process parameters while investigating their effect on the mechanical properties of a friction stir welded butt joint configuration of Polycarbonate. To minimize the total number of combinations a Central Composite Rotatable Design (CCRD) is used with three factors and two levels. The results have shown that the butt joints fabricated at a traverse speed of $14 \mathrm{~mm} / \mathrm{min}$, rotational speed of $1700 \mathrm{RPM}$ and with simple cylindrical conical tool geometry yielded the maximum ultimate tensile strength of 51.299 MPa.
\end{abstract}

Keywords: Butt joint, Friction Stir Welding, Polycarbonate, Ultimate Tensile Strength

\section{INTRODUCTION}

$\mathrm{W}$ elding is a metal joining process which is generally performed by fusing the adjoining surfaces while adding some additional filler material. Having been performed at very high temperatures, the welded joints always require to be shielded while in molten state to avoid oxidation and any other contamination that may damage the overall strength of joint. Shielded Metal Arc Welding, Gas Metal Arc Welding, Flux Cored Arc Welding, Gas Tungsten Arc Welding, Oxy-Fuel Welding, etc. are some of the examples where the welded joints require proper shielding. Fusion welding, despite being quick and generally less expensive, carries several disadvantages like grossly affecting the mechanical properties of the base metal, distortion of welded joints, spatter of molten metal, UV radiations etc. In view of these shortcomings a variety of solid-state welding approaches have been developed over the years that include Pressure Welding, Forge Welding, Friction Stir Welding etc. The FSW is an important technique of solid-state welding as it has several advantages associated to it e.g. inducing minimum effect on the mechanical properties of base material, reduced shrinkage and distortion, no spatter or UV radiations. FSW is performed with the help of a well-designed, non-

${ }^{1}$ Department of Mechanical Engineering, Wah Engineering College, University of Wah, Pakistan. Email: ${ }^{a}$ abidimtiaz115@gmail.com (Corresponding Author), badnan.tariq@wecuw.edu.pk, aajanjua@yahoo.com

${ }^{2}$ Department of Mechanical Engineering HITEC University Taxila, Pakistan. Email: fahad.butt@ hitecuni.edu.pk

${ }^{3}$ Department of Mechanical Engineering University of Engineering and Technology, Taxila, Pakistan.

Email: ammarkhawaja35@gmail.com

This is an open access article published by Mehran University of Engineering and Technology, Jamshoro under CC BY 4.0 International License. 
consumable pin profile tool and can be employed to join metals, non-metals and polymers.

FSW, a solid-state joining technique, was initially implemented at The Welding Institute (TWI) in United Kingdom [1]. The basic idea was to generate heat at the tool by the combination of pressure and frictional forces to diffuse and merge the adjoining surfaces. FSW requires a comparatively lesser amount of heat for joining the surfaces thus eliminates the chances of distortion and other welding flaws. Dashatan at al. [2] concluded that FSW, in addition to be environment friendly, has also proved to be economical as it does not require any filler material and shielding gas. The ability of FSW to weld even non-metals and polymers have made this method even more useful and important in industry. This has increased the application of polymers in the automotive, electronics, aerospace and packaging industries due to their lighter weight and higher strength to weight ratio [3].

Modern welding equipment are generally far more expensive than conventional joining techniques i.e. adhesive and mechanical fastening, that is why it limits their scope of application [4]. However, better joining strengths can be achieved with a comparatively lower investment by using FSW as there is no requirement of filler material and shielding gas. Also, through proper positioning and alignment of the welding tool and specimens, better joint formation can be surely achieved [5]. Reynolds et al. [6] carried out FSW of a $3.2 \mathrm{~mm}$ thick SS alloy at a single welding speed in combination with two different rotational speeds. They concluded that higher rotational speed responds with a higher energy input per unit of weld's length thus making the process applicable to higher melting alloys too. Mishra et al. [7] described that the preferred advantages of FSW are higher joining speeds, autogenous welding, improved metallurgical properties, and reduced skilled manpower dependencies. Scialpi et al. [8] conducted experiments on 9mm Polypropylene (PP) sheets. They used a Design Of Experiments (DOE) based analysis to study the effect of process parameters on the dimensions of Heat Affected Zone (HAZ) and strength of joint developed. They concluded that better quality and strength was achieved in FSW as compared to conventional welding techniques. Eslami et al. [9] studied the effect of different tool geometries on joint's strength of dissimilar PP and Polystyrene (PS) polymers. They observed that a stationary tool with two sleeves produced a stronger weld with good surface quality. They also came up with the conclusion that behavior of polymers is different from metals and therefore similar strength, in both materials, is difficult to obtain even with the same tool geometry.

Mehta et al. [10] developed an approach for the FSW of two dissimilar materials (Copper and AA6061T651) and observed the effect of process parameters on welded joints. They argued that a defect free joint having a maximum strength of $133 \mathrm{MPa}$ could be developed by using cylindrical tool pin profile. They also observed that with increase in the shoulder diameter and tilt angle, the plunge load also increased. Derazkola et al. [11] stated that rotating pin geometry is the main influence for material flow and attaining the peak temperature for high strength joints. They also observed that heat generated at the tool shoulder, pin surface and pin top have a direct relationship with the number of revolutions. Rane and Yadav [12] effectively employed FSW on two dissimilar materials i.e. Aluminum alloy and $\mathrm{Cu}$ alloy sheets of $6 \mathrm{~mm}$ thickness. They observed that maximum hardness and strength was achieved at mid-level values of both the considered parameters (traversing speed and feed). Oyedemi et al. [13] concluded that response of tri-flute conical tool was better than the other profiles. They also observed that welding force is approximately proportional to pin surface area and inverted tool ensures better results in welding regions. Huanga et al. [14] used a threaded tapered profile tool for triple facets FSW of Polyether Ether Ketone (PEEK) and Al alloy while verifying the soundness of joint formation. Panaskar et al. [15] studied the joints formed by FSW in case of different types of polymers i.e. Polyethylene (PE), Nylon, PP, High Density Polyethylene (HDPE), Polyvinylidene (PVDF), and Polyethylene Terephthalate (PETG). They observed that good quality butt joints were developed by FSW in HDPE. Sahu et al. [16] used three different tool geometries with varying traverse and rotational speeds while applying FSW on PE sheets. They achieved a maximum of $59.82 \%$ weld strength by using square pin tool. Gao et al. [17] carried out the FSW of Acrylonitrile Butadiene Styrene (ABS) and 
Polycarbonate (PC) $(200 \mathrm{~mm}$ x $200 \mathrm{~mm}$ x $4 \mathrm{~mm}$ size plates) in a submersible tank and attained a maximum strength of 19.2 $\mathrm{MPa}$ with a tapered profile tool using a combination of best experimented parameters. Sadeghian et al. [18] analyzed the FSW response of ABS sheets by experimental and statistical approaches. RSM with Central Composite Design (CCD) was used utilizing four factors, first with three levels and then with two levels of block parameters (i.e. cylindrical and conical pin). $101 \%$ and $99 \%$ higher strength was achieved from conical and cylindrical pinned tools, respectively.

Lambiase et al. [19] studied the effect of varying process parameters on FSW of Polycarbonate sheets. They carried out a single lap shear test to determine the mechanical strength of joints. Two full factorial designs were developed for experimental analysis. Also, an ANN model was developed to compare the experimental results and model predictions. The results showed that all the considered parameters did not have a similar impact on the joint strength. Mostafapour et al. [20] also analyzed the effect of process parameters on HDPE sheets while employing heat assisted FSW and carrying out the structural and mechanical testing of joints. They came up with the conclusions that rotational speed of tool has a significant role in welded joint's strength and a traversing speed of $25 \mathrm{~mm} / \mathrm{min}$ was found to be the optimum value for Polyethylene sheets. Another study that investigated the effect of parameters on joint strength was carried out by Astarita et al. [21]. They butt welded a $3 \mathrm{~mm}$ thick Polycarbonate sheet through FSW and achieved a maximum of $75 \%$ of the base material's strength.

Hajideh et al. [22] conducted a successful FSW of 8 $\mathrm{mm}$ thick sheets of dissimilar materials -Polymethyl Methacrylate (PMMA) and PC. $98 \%$ of PC base material joint was achieved. The effect of process parameters on weld strength and hardness followed a similar trend. Hasanzadeh et al. [23] worked on the inclusion of Alumina nano particles in Polycarbonate. Four different percentages of $0,1,2$ and 3 were experimentally utilized to conclude the effect on strength and hardness of $3.6 \mathrm{~mm}$ thick specimens. $01 \%$ weightage of Nano Alumina resulted in greatest strength, whereas, $0 \%$ weightage produced the greatest hardness in welded specimens. Also, it was observed that welding parameters did not have significant role in enhancing the mechanical properties of nano composite specimens. Kim et al. [24] studied the FSW of Aluminum A6005 sheets extruded in $4.8 \mathrm{~mm}$ thickness in butt joint formation. Process parameters selected to optimize the process were rotational speed, welding speed and tilt angle.

Palanivel et al. [25] applied RSM to optimize the independent parameters in FSW. Model fitness was checked by ANOVA and its F-value depicted the significance of the model and determined the noise factor. The value of $\mathrm{R}^{2}$ determined the fitness of the model and it ranged from 0 to 1 . Scatter diagram was used to compare the observed and predicted values and for checking the empirical model. Dhancholia et al. [26] studied the FSW of AA 6061 and 7039 Aluminum alloys considering the process parameters of rotational speed, welding speed and their effects on tensile, yield, impact strength and hardness. A CCD for RSM using two factors and two levels was applied to optimize the parameters. Optimized rotational and welding speeds were perceived as significant factors. By applying the optimization technique, the mechanical tests of buttwelded, dis-similar joints achieved $95 \%$ confidence level. It was observed that the rotational and welding speeds had a significant impact on the over all results. In the FSW, process parameters influence the weld properties. This behavior of process parameters effecting the mechanical properties, material flow and microstructure formation of Friction Stir Welded joints of metals and composites have been illustrated in numerous research studies [27]. In addition, Payganeh et al. [28] welded the Polypropylene with $30 \%$ Glass Fiber (GF) in a square butt joint configuration. It was observed that the tool pin geometry had an outstanding effect on the mechanical strength of joints. Panneerselvam et al. [29] found that right and left-handed threaded pin profile tool and the direction of tool rotation also influence the weld strength.

It is apparent from the literature review, presented here, that FSW has been rarely used for developing butt welded joints in Polycarbonates. Also, the application of FSW to Butt welded configurations of Polycarbonate is even more rare when it comes to using an optimized combination of the parameters, 
which significantly affect the strength of welded joints, is concerned. Being motivated by this gap in research an approach, based on RSM in combination with $\mathrm{CCD}$, is developed during this research which maximizes the weld strength by optimizing the combination of some significant process parameters like traversing speed, rotational speed, and tool geometry. 3D plot effects and ANOVA are used to verify and present the optimal level for each parameter.

\section{METHODOLOGY}

The methodology adopted during this research is presented in the form of a flow diagram as shown in Fig. 1. The flow diagram elaborates the complete procedure followed during the research from identifying and examining the experimental needs till conducting the confirmation experiments of optimum parameters.

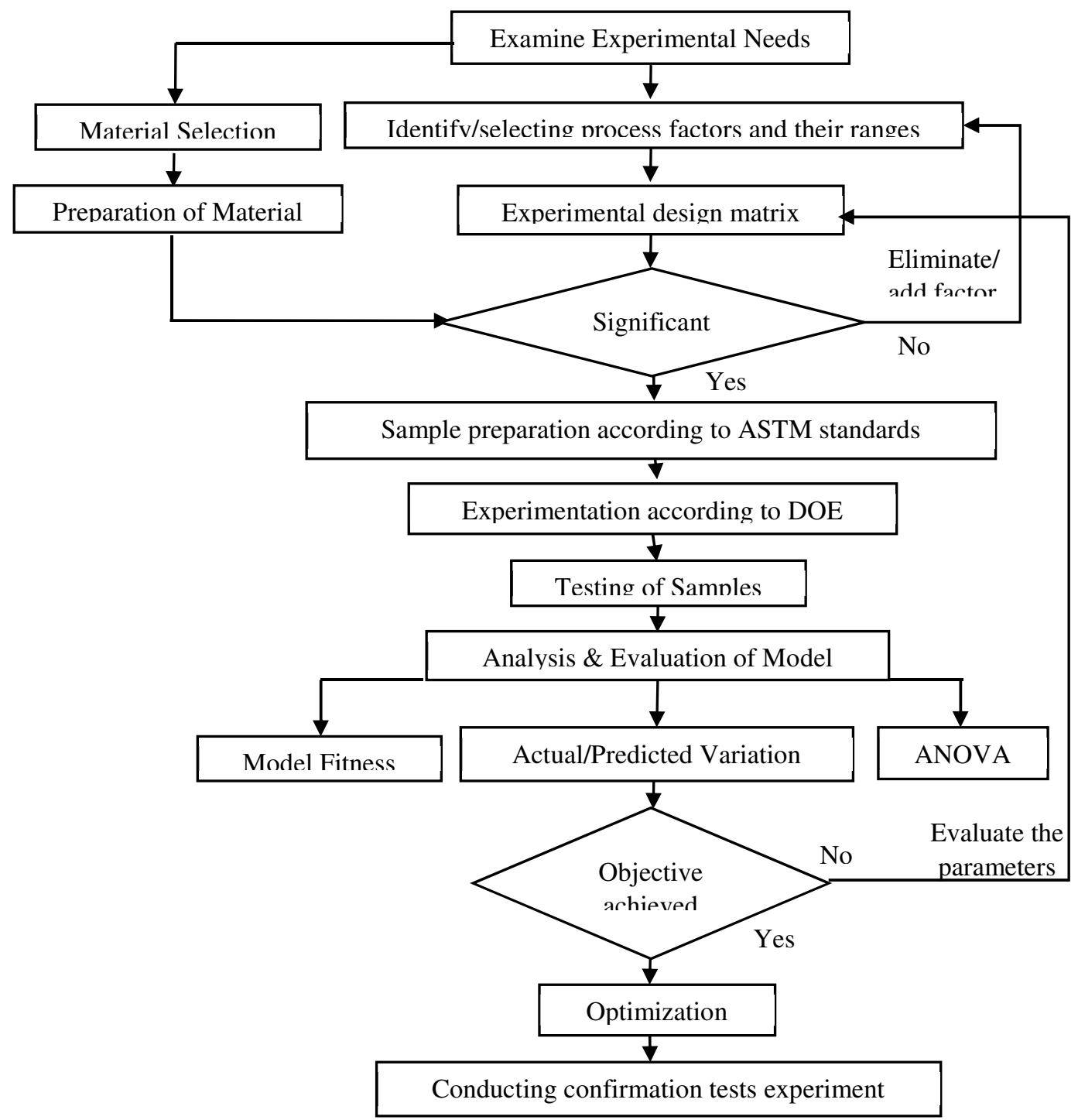

Fig. 1: Methodology

\section{PROCEDURE}

To implement the overall methodology presented in Fig. 1, stepwise procedure adopted is outlined as follows:
1. Design and fabrication of a mold to cast PC plates of desired dimensions

2. Devising a fixture to hold the PC plates in a fixed position while welding 
3. Manufacturing of FSW tool to be later on used for the purpose of welding

4. Selection of process parameters

5. Development of design matrix

6. Friction stir welding (FSW)

7. Specimen preparation

8. Mechanical testing

9. Development of empirical model

10. Analysis of Variance (ANOVA)

11. Confirmation for the adequacy of model

\subsection{Manufacturing of Mold}

The first step in the methodology was to design and fabricate a mold to get desired dimensions of PC plates. The size of plates was required to be kept at $100 \mathrm{~mm} \times 50 \mathrm{~mm} \times 4 \mathrm{~mm}$ keeping in view the application of producing butt welded joint through FSW. First a solid model was designed, created, assembled and analyzed using CAD Modeling software as shown in Fig. 2. Fig. 3 shows the mold, manufactured on a 3-axis CNC milling machine and finally assembled.

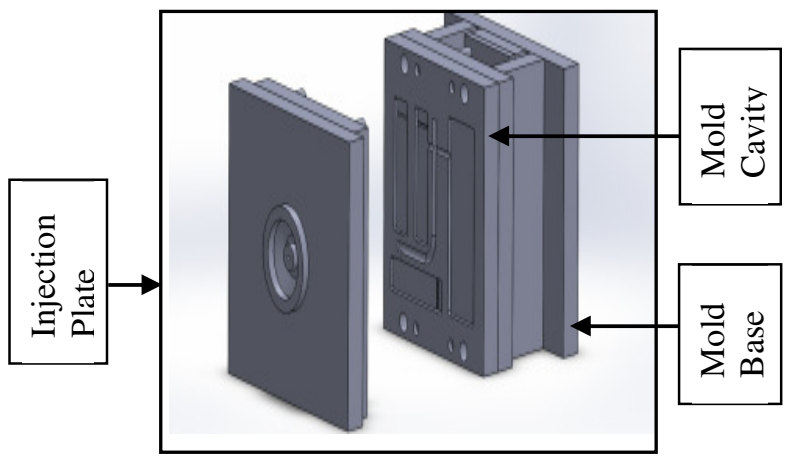

Fig. 2: Mold Assembly in Designing Software

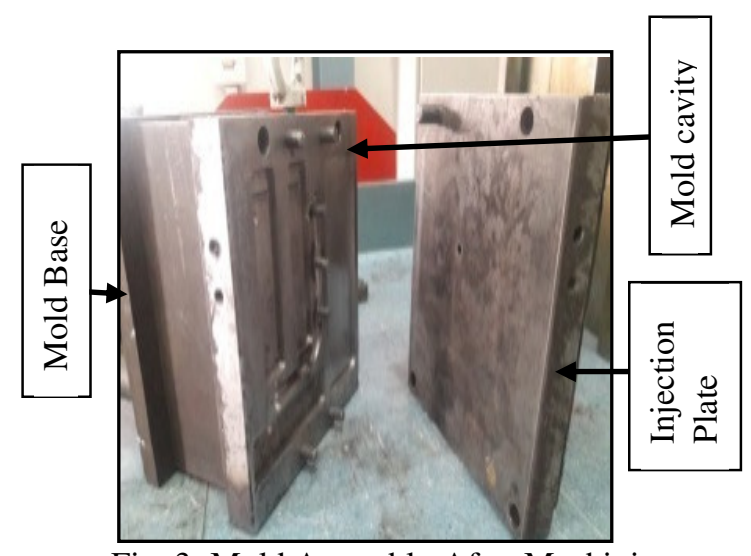

Fig. 3: Mold Assembly After Machining
Further, this research used pure natural polycarbonate material, for molding plates of the required dimensions. An injection molding machine was used to cast and extract the plates from the cavity of mold to avoid sink marks, flow lines and vacuum voids etc.

\subsection{Manufacturing of Fixture}

Fig. 4 shows the type of fixture used during this research for positioning, support and properly align the plates for FSW process.

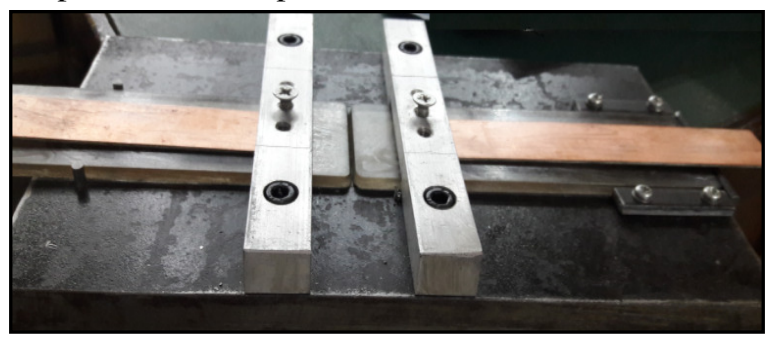

Fig. 4: Fixture for Clamping PC Plates

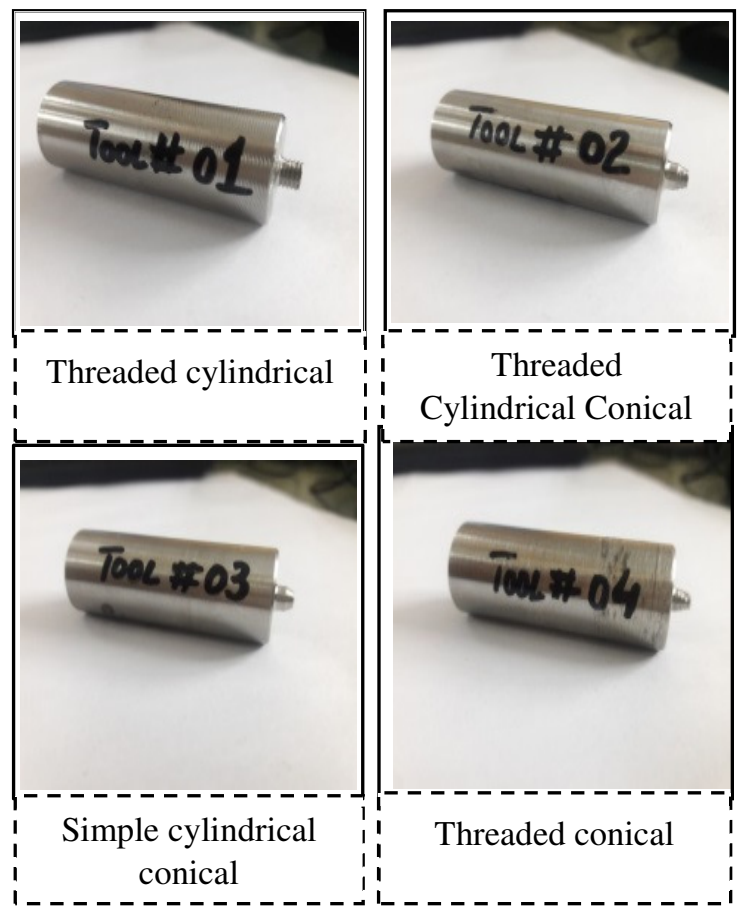

Fig. 5: Tool Geometries

\subsection{Manufacturing of FSW tools}

In order to investigate the effect of tool geometry on the weld strength, four tools with different pin geometries of $1 \mathrm{~mm}$ pitch, $1 \mathrm{~mm}$ depth of thread and a taper of 15 degree were manufactured and used in experiments. The details of different tool geometries, 
used here, are shown in Fig. 5 and Table 1. The manufacturing of these tools was carried out on a CNC turning machine using high-speed steel.

\subsection{Selection of Process parameters}

The process parameters of FSW, having major influence on the quality and strength of joints, are rotational speed, traverse speed and tool geometry [30]. Therefore, during this research FSW was carried out at a traversing speed from 14 to $35 \mathrm{~mm} / \mathrm{min}$ and rotational speed of 950 to 1700 RPM while using different tool geometries, as shown in Table 2 and Table 3.

\begin{tabular}{|c|c|c|c|c|}
\hline \multicolumn{5}{|c|}{ Table 1: Tool Specifications } \\
\hline Tool No & Description of Pin & $\begin{array}{c}\text { Length } \\
\text { of Pin } \\
(\mathrm{mm})\end{array}$ & $\begin{array}{c}\text { Dia } \\
\text { of } \\
\text { Pin } \\
(\mathrm{mm})\end{array}$ & $\begin{array}{c}\text { Dia of } \\
\text { Shoulder } \\
(\mathrm{mm})\end{array}$ \\
\hline 1 & $\begin{array}{c}\text { Threaded } \\
\text { Cylindrical }\end{array}$ & 3.8 & 4 & 16 \\
\hline 2 & $\begin{array}{c}\text { Threaded } \\
\text { Cylindrical } \\
\text { Conical }\end{array}$ & 3.8 & 4 & 16 \\
\hline 3 & $\begin{array}{c}\text { Simple } \\
\text { Cylindrical } \\
\text { Conical }\end{array}$ & 3.8 & 4 & 16 \\
\hline 4 & Threaded Conical & 3.8 & 4 & 16 \\
\hline
\end{tabular}

\begin{tabular}{|c|c|c|c|}
\hline \multicolumn{3}{|c|}{ Table 2: List of a Continuous Factor } \\
\cline { 3 - 4 } PARAMETER & \multirow{2}{*}{ UNITS } & LOW & HIGH \\
\hline Traverse Speed & $\mathrm{mm} / \mathrm{min}$ & 14 & 35 \\
\hline Rotational Speed & RPM & 950 & 1700 \\
\hline
\end{tabular}

\subsection{Development of Design Matrix}

RSM was used to develop the regression models whereas CCD was used for the analysis of current surface response based on three factors: two levels for two continuous factors and four levels for one categorical factor to allow the estimation of all first order and two-factor interaction terms. The rotation of design remained dependent upon the axial points and distance from the center. The design contained 56 sets of runs and regression models were developed by using these experimental runs. The total number of experiments were calculated using equation (1)
No. of experiments $=\left(2^{n}+2 n+n_{c}\right)$

where $\mathrm{n}$ is the number of continuous factors. In this research, two continuous factors (Rotational speed and Traversing speed) were used. Also, $\mathrm{n}_{\mathrm{c}}$ is the number of center points and a total of six center points were used during these experiments. Also, a categorical factor (Tool geometry) was also used in this research work while multiplying each experiment by a number of levels of that factor.

\subsection{Friction Stir Welding Procedure}

To execute the process of FSW, a CNC milling machine was used during this research, to achieve different traversing and rotational speeds. The molded PC plates were clamped in the designed fixture in a butt joint configuration. The tool was allowed to plunge slowly into the plates and weld was produced using the designed parameters. Later on, once the FSW process was completed, a sufficient amount of time was given to the weld plates, while being fastened in the fixture, to cool down in order to avoid any distortion due to the heat generated during the process.

\subsection{Specimen Preparation}

The tensile samples were prepared according to ASTM D638 standard, as shown in Fig. 6.

\subsection{Mechanical Testing}

Fig. 7 shows all of the 56 experiments designed and to be tested on the tensile testing machine to determine the strength of joints. Fig. 8 shows the apparatus setup of the tensile testing specimen.

All the experiments were conducted as per CCD. Table 4 presents the response (UTS) obtained from the PC butt joint specimens along with the values of the influencing parameters. Threaded cylindrical, threaded cylindrical conical and simple cylindrical conical tools recorded abrupt changes in tensile strength unlike threaded conical tool.

\begin{tabular}{|c|c|c|c|c|}
\hline \multicolumn{4}{|c|}{ Table 3: List of Categorical Factors } \\
\hline \multirow{2}{*}{ PARAMETER } & \multicolumn{3}{|c|}{ LEVEL } \\
\cline { 2 - 4 } & LEVEL 1 & LEVEL 2 & LEVEL 3 \\
\hline Tool Geometry & Threaded Cylindrical & Threaded Cylindrical Conical & Simple Cylindrical Conical & Threaded Conical \\
\hline
\end{tabular}




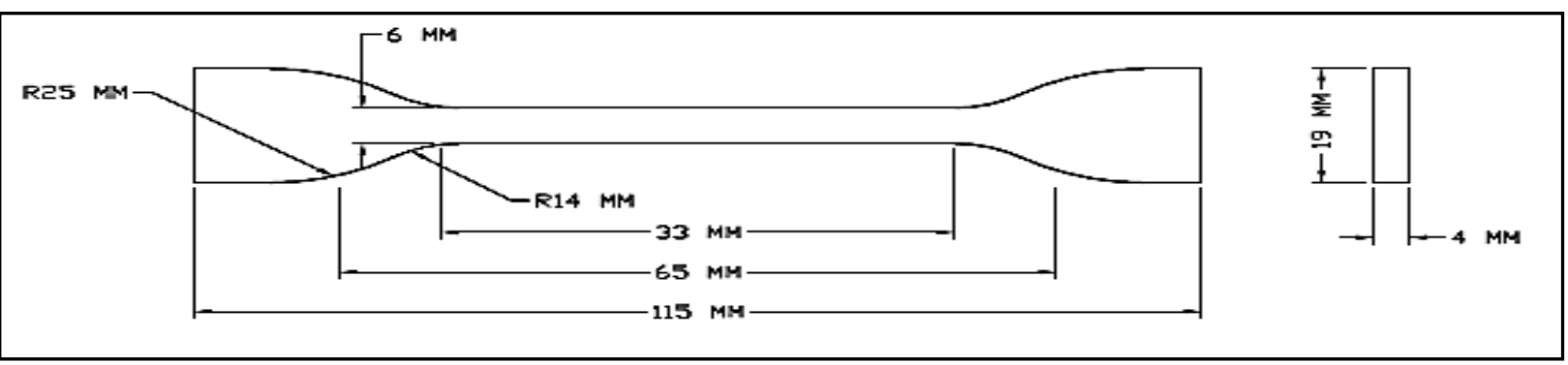

Fig. 06: Specimen Dimensions

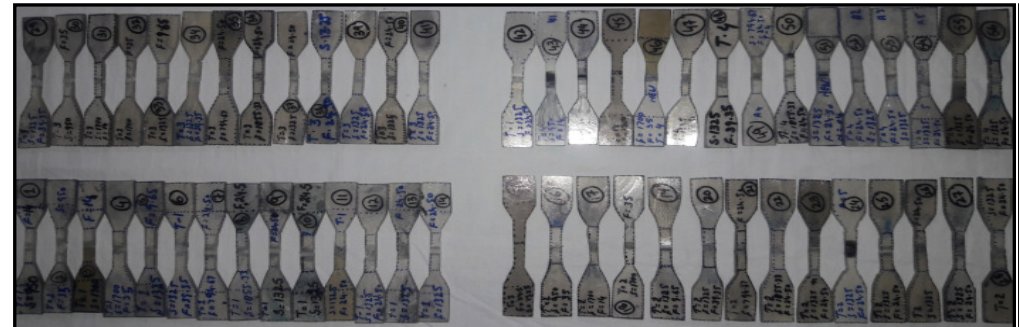

Fig. 7: Tensile Testing Specimens

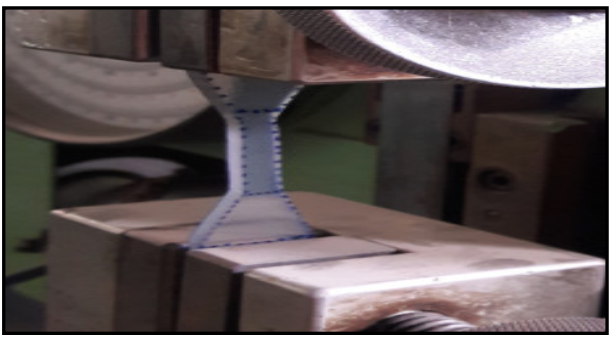

Fig. 8: Apparatus Setup of the Tensile Testing Specimen

\begin{tabular}{|c|c|c|c|c|}
\hline \multicolumn{5}{|c|}{ Table 4: Response (Ultimate Tensile Strength (UTS)) Results } \\
\hline Run & $\begin{array}{l}\text { Traverse speed } \\
(\mathrm{mm} / \mathrm{min})\end{array}$ & $\begin{array}{l}\text { Rotational speed } \\
\text { (RPM) }\end{array}$ & Tool Geometry & $\begin{array}{c}\text { Tensile Strength } \\
\text { (MPa) }\end{array}$ \\
\hline 1 & 24.50 & 1325.00 & Simple Cylindrical Conical & 28.0241 \\
\hline 2 & 24.50 & 1855.33 & Threaded Cylindrical & 16.8953 \\
\hline 3 & 24.50 & 1325.00 & Threaded Conical & 34.6987 \\
\hline 4 & 39.35 & 1325.00 & Threaded Cylindrical Conical & 13.946 \\
\hline 5 & 24.50 & 1325.00 & Threaded Cylindrical Conical & 14.4816 \\
\hline$\overline{6} 6$ & 35.00 & 950.00 & Simple Cylindrical Conical & 12.0875 \\
\hline$\overline{77}$ & 35.00 & 1700.00 & Threaded Conical & 20.15 \\
\hline 8 & 14.00 & 1700.00 & Simple Cylindrical Conical & 46.152 \\
\hline 9 & 24.50 & 1855.33 & Threaded Conical & 31.248 \\
\hline 10 & 35.00 & 950.00 & Threaded Conical & 41.9 \\
\hline 11 & 24.50 & 1855.33 & Simple Cylindrical Conical & 52.5208 \\
\hline 12 & 9.65 & 1325.00 & Threaded Cylindrical Conical & 26.0173 \\
\hline 13 & 24.50 & 1325.00 & Simple Cylindrical Conical & 23.0241 \\
\hline 14 & 24.50 & 1325.00 & "Threaded Cylindrical Conical & 14.4816 \\
\hline 15 & 24.50 & 1325.00 & Threaded Conical & 28.6988 \\
\hline 16 & 24.50 & 1325.00 & Simple Cylindrical Conical & 20.0241 \\
\hline 17 & 24.50 & 1325.00 & Threaded Conical & 32.6987 \\
\hline 18 & 24.50 & 1325.00 & Threaded Cylindrical & 25.7491 \\
\hline 19 & 14.00 & 1700.00 & Threaded Cylindrical & 32.692 \\
\hline 20 & 24.50 & 794.67 & Simple Cylindrical Conical & 9.4725 \\
\hline 21 & 35.00 & 950.00 & Threaded Cylindrical & 39.9975 \\
\hline 22 & 24.50 & 1325.00 & Threaded Cylindrical Conical & 17.4816 \\
\hline 23 & 9.65 & 1325.00 & Threaded Cylindrical & 26.7303 \\
\hline 24 & 24.50 & 1325.00 & Threaded Conical & 31.6988 \\
\hline 25 & 24.50 & 1325.00 & Threaded Cylindrical Conical & 19.4816 \\
\hline 26 & 24.50 & 1325.00 & Threaded Cylindrical Conical & 17.4816 \\
\hline
\end{tabular}

Mehran University Research Journal of Engineering and Technology, Vol. 40, No. 1, January 2021 [p-ISSN: 0254-7821, e-ISSN: 2413-7219] 


\begin{tabular}{|c|c|c|c|c|}
\hline 27 & 24.50 & 1325.00 & Threaded Cylindrical & 20.7491 \\
\hline 28 & 14.00 & 950.00 & Threaded Cylindrical & 28.022 \\
\hline 29 & 24.50 & 1325.00 & Threaded Conical & 33.6987 \\
\hline 30 & 24.50 & 1325.00 & Threaded Cylindrical & 26.7491 \\
\hline 31 & 14.00 & 1700.00 & Threaded Cylindrical Conical & 25.222 \\
\hline 32 & 24.50 & 1325.00 & Threaded Cylindrical Conical & 23.4816 \\
\hline 33 & 14.00 & 1700.00 & Threaded Conical & 41.61 \\
\hline 34 & 35.00 & 1700.00 & Threaded Cylindrical Conical & 4.44 \\
\hline 35 & 24.50 & 794.67 & Threaded Cylindrical Conical & 21.9337 \\
\hline 36 & 35.00 & 1700.00 & Simple Cylindrical Conical & 30.025 \\
\hline 37 & 9.65 & 1325.00 & Threaded Conical & 35.6016 \\
\hline 38 & 39.35 & 1325.00 & Threaded Conical & 21.7959 \\
\hline 39 & 14.00 & 950.00 & Simple Cylindrical Conical & 3.832 \\
\hline 40 & 35.00 & 950.00 & Threaded Cylindrical Conical & 27.9325 \\
\hline 41 & 24.50 & 1325.00 & Threaded Cylindrical & 20.7491 \\
\hline 42 & 24.50 & 1325.00 & Simple Cylindrical Conical & 22.0241 \\
\hline 43 & 14.00 & 950.00 & Threaded Conical & 28.135 \\
\hline 44 & 39.35 & 1325.00 & Threaded Cylindrical & 21.768 \\
\hline 45 & 24.50 & 1855.33 & Threaded Cylindrical Conical & 15.0295 \\
\hline 46 & 39.35 & 1325.00 & Simple Cylindrical Conical & 15.291 \\
\hline 47 & 14.00 & 950.00 & Threaded Cylindrical Conical & 17.327 \\
\hline 48 & 24.50 & 1325.00 & Simple Cylindrical Conical & 26.0241 \\
\hline 49 & 24.50 & 1325.00 & Threaded Cylindrical & 20.7491 \\
\hline 50 & 24.50 & 1325.00 & Simple Cylindrical Conical & 26.0241 \\
\hline 51 & 35.00 & 1700.00 & Threaded Cylindrical & 7.285 \\
\hline 52 & 24.50 & 1325.00 & Threaded Conical & 28.6988 \\
\hline 53 & 24.50 & 1325.00 & Threaded Cylindrical & 27.7491 \\
\hline 54 & 24.50 & 794.67 & Threaded Cylindrical & 34.603 \\
\hline 55 & 24.50 & 794.67 & Threaded Conical & 30.1495 \\
\hline 56 & 9.65 & 1325.00 & Simple Cylindrical Conical & 29.7573 \\
\hline
\end{tabular}

\subsection{Development of Empirical Model}

Using of the coded factor equations, response for the given level of each factor was predicted. High and low, levels of the coded factor were +1 and -1 . Comparison of factor coefficients on the relative impact of factors can be identified by the coded equation.

Tensile strength $(\mathrm{UTS})=24.90-3.23 \times \mathrm{A}+1.12 \times \mathrm{B}$ $+0.14 \times \mathrm{C}[1]-6.42 \times \mathrm{C}[2]-0.31 \times \mathrm{C}[3]-8.02 \times \mathrm{AB}$ $+0.67 \times \mathrm{AC}[1]-0.18 \times \mathrm{AC}[2]-0.31 \times \mathrm{AC}[3]-7.76 \times \mathrm{BC}[1]-$ $4.29 \times \mathrm{BC}[2]+14.02 \times \mathrm{BC}[3]$

Final equations in terms of actual factors for four tool geometries are:

Threaded cylindrical:
Response $($ UTS $)=11.70501+2.45656 \times$ Traverse speed+0.032230 $\times$ Rotational speed $-2.03774 \mathrm{E}-$ $003 \times$ Traverse speed $\times$ Rotational speed Threaded cylindrical:

Response $($ UTS $)=11.70501+2.45656 \times$ Traverse speed $+0.032230 \times$ Rotational speed $-2.03774 \mathrm{E}$ $003 \times$ Traverse speed $\times$ Rotational speed

Threaded Cylindrical Conical:

Response $($ UTS $)=-28.52015+2.37562 \times$ Traverse speed+0.041471 $\times$ Rotational speed-2.03774E$003 \times$ Traverse speed $\times$ Rotational speed

Simple Cylindrical Conical:

Response $($ UTS $)=-86.79770+2.36274 \times$ Traverse speed $+0.090304 \times$ Rotational speed-2.03774E$003 \times$ Traverse speed $\times$ Rotational speed 
Threaded Conical:

Response $($ UTS $)=-23.75796+2.37596 \times$ Traverse speed+0.047684 $\times$ Rotational speed-2.03774E-

$003 \times$ Traverse speed $\times$ Rotational speed

Analyses of the predicted response from regression equations, as calculated from the design of experiments, identified the optimal conditions.

\subsection{Analysis of Variance (ANOVA)}

By performing ANOVA, the significance of process parameters was identified. The model terms are found to be significant if the Value of "Prob $>$ F" is less than 0.0500. The significant model terms are A, B, C, AB, and $\mathrm{BC}$ in this case (Table 5). They become insignificant if the values are greater than 0.1000 . Relative to a pure error, the Lack of Fit is not significant when the "Lack of Fit F-value" of the model is 1.153 . Due to large noise found, a $37.5 \%$ chance is that a "Lack of Fit F-value" would be recorded. Non-significant Lack of Fit is good for the model to be termed as fit.

\subsection{Adequacy of Model}

The accuracy of the model can be confirmed by the value of $R^{2}$. Model is termed as accurate when the $R^{2}$ value is closest to unity. In this case, the value of $R^{2}=$ 0.916, which is closest to unity as shown in Table 6, suggests that the model is accurate enough. Fig. 9 shows that all points lie on the trend line, indicating the normal distribution of errors. The predicted response values of the model are well in agreement with the actual values which is shown in Fig. 10, which determines a good fit of model.

\begin{tabular}{|c|c|c|c|c|c|c|}
\hline \multicolumn{7}{|c|}{ Table 5: ANOVA for Response Surface 2FI Model } \\
\hline Source & $\begin{array}{c}\text { Sum of } \\
\text { Squares }\end{array}$ & df & $\begin{array}{c}\text { Mean } \\
\text { Square }\end{array}$ & $\begin{array}{c}\mathrm{F} \\
\text { Value }\end{array}$ & $\begin{array}{c}\text { p-value } \\
\text { Prob }>F\end{array}$ & Model Checkness \\
\hline Model & 4825.99 & 12 & 402.165 & 39.080 & $3.56707 \mathrm{E}-19$ & \multirow{8}{*}{ Significant } \\
\hline A-Traverse speed & 333.118 & 1 & 333.118 & 32.370 & $1.032 \mathrm{E}-06$ & \\
\hline B-Rotational speed & 40.429 & 1 & 40.429 & 3.928 & 0.053 & \\
\hline C-Tool Geometry & 1185.36 & 3 & 395.119 & 38.395 & $3.1491 \mathrm{E}-12$ & \\
\hline $\mathrm{AB}$ & 1030.049 & 1 & 1030.048 & 100.095 & $8.508 \mathrm{E}-13$ & \\
\hline $\mathrm{AC}$ & 4.892 & 3 & 1.630 & 0.158 & 0.923 & \\
\hline $\mathrm{BC}$ & 2232.14 & 3 & 744.046 & 72.302 & $7.757 \mathrm{E}-17$ & \\
\hline Residual & 442.500 & 43 & 10.290 & & & \\
\hline Lack of Fit & 252.333 & 23 & 10.971 & 1.153 & 0.375 & \multirow{3}{*}{ not significant } \\
\hline Pure Error & 190.166 & 20 & 9.508 & & & \\
\hline Cor Total & 5268.49 & 55 & & & & \\
\hline
\end{tabular}

\begin{tabular}{|c|c|c|c|c|c|c|}
\hline \multicolumn{7}{|c|}{ Table 6: Model Summary Statistics } \\
\hline Source & $\begin{array}{c}\text { Std. } \\
\text { Dev. }\end{array}$ & R-Squared & $\begin{array}{c}\text { Adjusted } \\
\text { R-Squared }\end{array}$ & $\begin{array}{c}\text { Predicted } \\
\text { R-Squared }\end{array}$ & PRESS & Model Selection \\
\hline Linear & 8.613 & 0.295 & 0.225 & 0.068 & 4910.206 & \\
\hline 2FI & 3.207 & 0.916 & 0.892 & 0.848 & 796.912 & Suggested \\
\hline Quadratic & 3.135 & 0.923 & 0.897 & 0.846 & 807.818 & \\
\hline Cubic & 3.069 & 0.946 & 0.901 & 0.768 & 1220.387 & Aliased \\
\hline
\end{tabular}

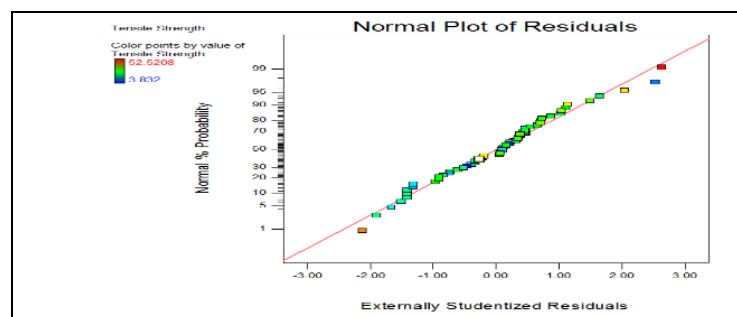

Fig. 9: The Normal Plot of Residuals for A Response (UTS)

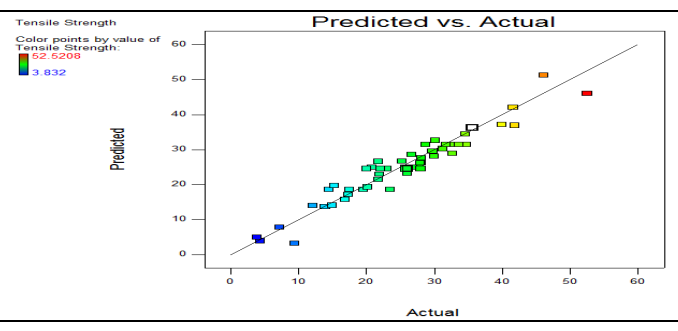

Fig. 10: Predicted Vs Actual For A Response (UTS)

\section{RESULTS \& DISCUSSIONS}

Finally, now it's time to substantiate the effect of different process parameters (traverse speed, rotational speed and tool geometry) on the overall strength of the joint. For this purpose, the discussion is sequentially arranged by considering different tool geometries (one by one) in combination with varying ol. 40, No. 1, January 2021 [p-ISSN: 0254-7821, e-ISSN: 2413-7219] 
traverse and rotational speeds and discussing their effect on tensile strength of the friction stir welded joints.

\subsection{Threaded Cylindrical Tool}

Fig. 11 shows a 3D interacted graph for traverse and rotational speed against tensile strength when a threaded cylindrical tool was used. It can be observed from the graph (Fig. 11) that the tensile strength initially increases up to a certain limit, with the increase in the values of both corresponding parameters, and then starts decreasing with any further increase in the values parameters (traverse and rotational speed). From the graph it is also evident that the higher value of tensile strength has been achieved when the rotational speed is low, and the traversing speed is high. The reason for this behaviour is that at low rotational and traverse speeds, lesser amount of heat is generated which consequently does not facilitate the material of the two adjoining surfaces to get mixed up adequately and thus results in poor quality of welds. Whereas, at higher rotational and traverse speed, although the material melts quickly due to higher heat generation, but at the same time the higher speeds does not allow the material to settle down properly thus causing porosity in the weld joint. Zafar et al. [31] reported that welding parameters vary from polymer to polymer. Those having higher melting point and viscosity, require higher rotational and low traversing speeds to achieve sufficient heat and good joint strength.

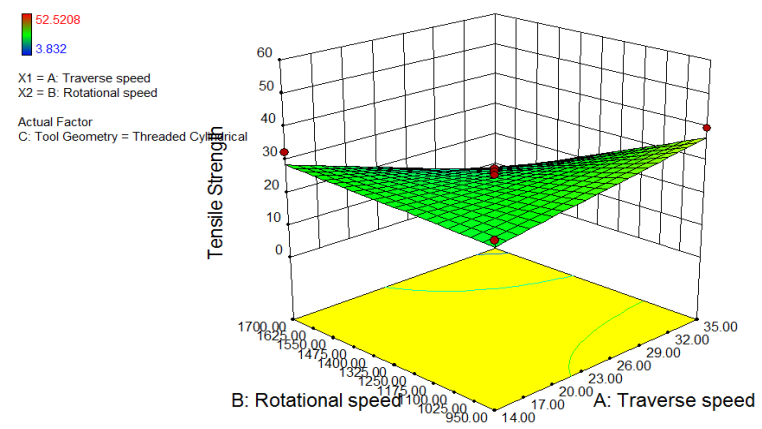

Fig. 11: 3D-Graph Interaction of Traverse vs Rotational Speed for Tensile Strength with a Threaded Cylindrical Tool

\subsection{Threaded cylindrical conical tool}

Fig. 1 presents the effect of threaded cylindrical conical tool on the tensile strength of the welded joint for different rotational and traversing speeds. Here also, the tensile strength initially increases and then starts decreasing by further increasing the values of both speeds. At lower rotational speed and higher traversing speed and vice versa, the value of tensile strength remains the same. The reason for this behavior is because in both of these situations (lower rotational speed and higher traversing speed or otherwise) the amount of heat generation would be more or less the same thus generating similar results in terms of tensile strength.

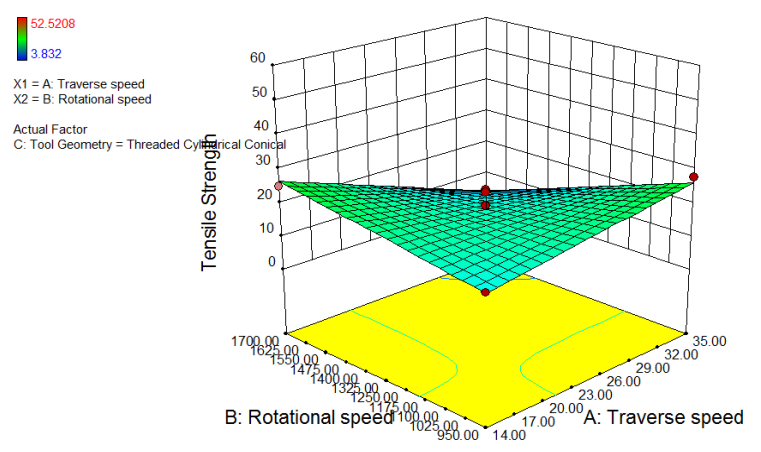

Fig. 12: 3D-Graph Interaction of Traverse Vs Rotational Speed for Tensile Strength with a Threaded Cylindrical Conical Tool

\subsection{Simple Cylindrical Conical Tool}

Fig. 13 generally presents a similar picture, observed in the previous two cases, of tensile strength increasing initially and then drops down gradually at a very slower rate with further increase in values of traversing and rotational speeds. However, a slightly

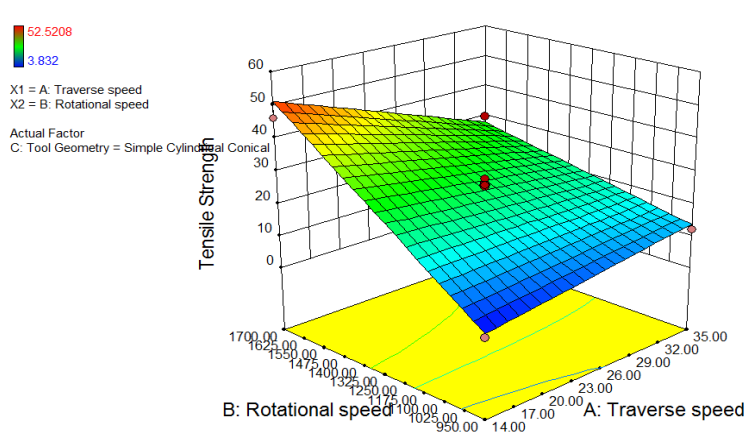

Fig. 13: 3D-Graph Interaction of Traverse vs Rotational Speed for Tensile Strength with a Simple Cylindrical Conical Tool

different aspect of this graph is that maximum tensile strength has been achieved at the highest rotational speed and lowest traversing speed. The reason for this behavior was investigated by Bilici et al. [32]. They concluded that the straight and tapered profiles have 
different stir zone thicknesses. The straight profile generates a lowest fracture load while tapered profile generates the highest fracture load. Further, excessive taper angle generates additional heat, which lowers the weld strength. Prashant et al. [33] reported that stepped conical tool produces efficient joint as compared to other profiles. It, also, improves material mixing and better material movement in the weld zone.

\subsection{Threaded Conical Tool}

The results of FSW while using threaded conical tool are presented in Fig. 14. From the figure (Fig. 14) it is evident that tensile strength of the welded joint remains maximum when either the traversing speed remains maximum against a corresponding lowest value of rotational speed or the other way around. In case the values of both the speeds i.e. rotational and traversing, are altered simultaneously form minimum to maximum, the variation in tensile strength is approximately the same as described in the previous cases. It (tensile strength) initially increases up to certain limit and then starts decreasing with further increase in the values of rotational and traversing speeds. Zafar et al. [31] and Eslami et al. [9] reported that the quality of welds generated by FSW with threaded conical tool have been very high having no porosity or voids. This is because threads around the probe facilitate the softened material, at the faying surfaces, to get mixed up properly thus generating a uniform weld seam free of voids. Bilici et al. [32] also determined the effects of threaded profile pin on the quality of welds. They observed that with an increase in the pitch length there occurs a corresponding decrease in the fracture load and consequently weakens the weld joints.

\section{OPTIMIZATION OF PROCESS PARAMETERS}

The use of optimized combination of process parameters is very essential for the FSW process as it improves the overall quality of welds and largely increases the tensile strength of the welded joints. Therefore, the objective of this research has also been to maximize the tensile strength of a friction stir welded joint by optimizing the combination of some critical process parameters. The results of different combinations are shown in Table 7 and Table 8. Optimum values of the parameters resulting in maximum tensile strength are mentioned in Table 08 and presented in ramps order in Fig. 15. Plot based on the desirability approach is also shown in Fig. 16.

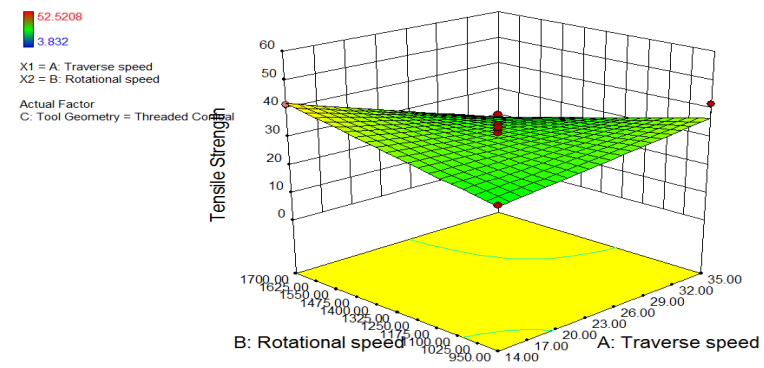

Fig. 14: 3D-Graph Interaction of Traverse vs Rotational Speed for Tensile Strength with a Threaded Conical Tool

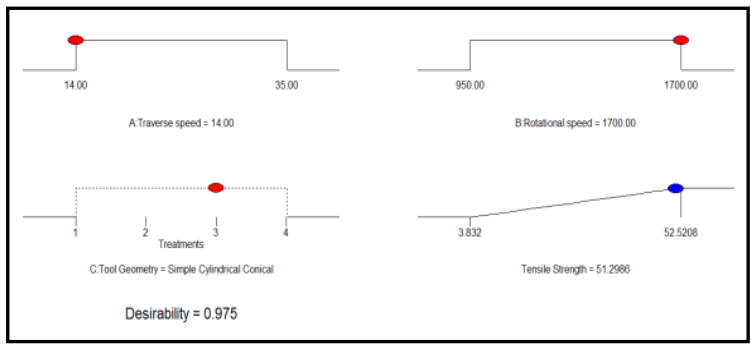

Fig. 15: Optimization in terms of Ramps Response

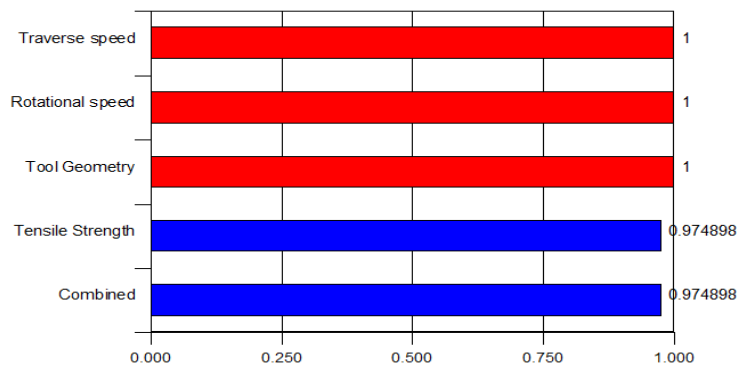

Fig. 16: Desirability Approach

\begin{tabular}{|c|c|c|c|c|c|c|}
\hline \multicolumn{9}{|c|}{ Table 7: Parametric Optimization Ranges } \\
\hline Name & Goal & Lower Limit & Upper Limit & Lower Weight & Upper Weight & Importance \\
\hline Traverse speed(mm/min) & is in range & 14 & 35 & 1 & 1 & 3 \\
\hline Rotational speed(rpm) & is in range & 950 & 1700 & 1 & 1 & 3 \\
\hline Tool Geometry & is in range & Threaded Cylindrical & Threaded Conical & 1 & 1 & 3 \\
\hline Tensile Strength(MPa) & maximize & 3.832 & 52.520 & 1 & 1 & 3 \\
\hline
\end{tabular}

Mehran University Research Journal of Engineering and Technology, Vol. 40, No. 1, January 2021 [p-ISSN: 0254-7821, e-ISSN: 2413-7219] 


\begin{tabular}{|c|c|c|c|c|c|c|}
\hline \multicolumn{7}{|c|}{ Table 8: Optimization Table } \\
\hline No. & $\begin{array}{l}\text { Traverse speed } \\
(\mathrm{mm} / \mathrm{min})\end{array}$ & $\begin{array}{c}\text { Rotational speed } \\
(\mathrm{rpm})\end{array}$ & Tool Geometry & $\begin{array}{c}\text { Tensile Strength } \\
(\mathrm{MPa})\end{array}$ & \begin{tabular}{|c|} 
Desirability \\
$(\%)$
\end{tabular} & \\
\hline 1 & 14.000 & 1700.000 & Simple Cylindrical Conical & 51.299 & 0.975 & Selected \\
\hline 2 & 14.120 & 1700.000 & Simple Cylindrical Conical & 51.166 & 0.972 & \\
\hline 3 & 14.422 & 1699.999 & Simple Cylindrical Conical & 50.833 & 0.965 & \\
\hline 4 & 14.000 & 1700.000 & Threaded Conical & 42.070 & 0.785 & \\
\hline 5 & 14.000 & 1695.553 & Threaded Conical & 41.985 & 0.784 & \\
\hline 6 & 14.000 & 1687.917 & Threaded Conical & 41.839 & 0.781 & \\
\hline 7 & 14.000 & 1669.964 & Threaded Conical & 41.495 & 0.774 & \\
\hline 8 & 14.000 & 1586.248 & Threaded Conical & 39.891 & 0.741 & \\
\hline 9 & 35.000 & 950.000 & Threaded Cylindrical & 37.138 & 0.684 & \\
\hline 10 & 35.000 & 950.000 & Threaded Conical & 36.946 & 0.680 & \\
\hline 11 & 33.862 & 950.001 & Threaded Cylindrical & 36.546 & 0.672 & \\
\hline 12 & 23.656 & 950.000 & Threaded Cylindrical & 31.231 & 0.563 & \\
\hline 13 & 14.000 & 1700.000 & Threaded Cylindrical & 28.979 & 0.516 & \\
\hline 14 & 14.000 & 1700.000 & $\begin{array}{c}\text { Threaded Cylindrical } \\
\text { Conical }\end{array}$ & 26.741 & 0.471 & \\
\hline 15 & 35.000 & 950.000 & $\begin{array}{c}\text { Threaded Cylindrical } \\
\text { Conical }\end{array}$ & 26.269 & 0.461 & \\
\hline 16 & 14.990 & 1699.999 & $\begin{array}{c}\text { Threaded Cylindrical } \\
\text { Conical }\end{array}$ & 25.663 & 0.448 & \\
\hline 17 & 30.188 & 950.000 & $\begin{array}{c}\text { Threaded Cylindrical } \\
\text { Conical }\end{array}$ & 24.153 & 0.417 & \\
\hline
\end{tabular}

\subsection{Confirmation test}

In order to confirm the theoretical results, obtained during this research, four different confirmation tests were carried as listed in Table 9. To calculate the percentage of error in each test and confirm the accuracy of the model the following equation (Equation 08) was used.

Percentage error $=\frac{\text { Actual value }- \text { Predicted value }}{\text { Predicted value }}$

\begin{tabular}{|c|c|c|c|}
\hline \multicolumn{4}{|c|}{ Table 9: Confirmation Tests Parameters Selection } \\
\hline Run & $\begin{array}{c}\text { Traverse } \\
\text { Speed } \\
(\text { Mm/Min) }\end{array}$ & $\begin{array}{c}\text { Rotational } \\
\text { Speed } \\
(\text { Rpm })\end{array}$ & Tool Geometry \\
\hline 1 & 14 & 1700 & $\begin{array}{c}\text { Simple cylindrical } \\
\text { conical }\end{array}$ \\
\hline 2 & 35 & 950 & Threaded cylindrical \\
\hline 3 & 35 & 950 & Threaded conical \\
\hline 4 & 35 & 950 & $\begin{array}{c}\text { Threaded cylindrical } \\
\text { conical }\end{array}$ \\
\hline
\end{tabular}

The samples prepared for confirmation test are shown in Fig. 17 and 18. All confirmation tests were performed on the tensile testing machine. The results obtained are listed in Table10.

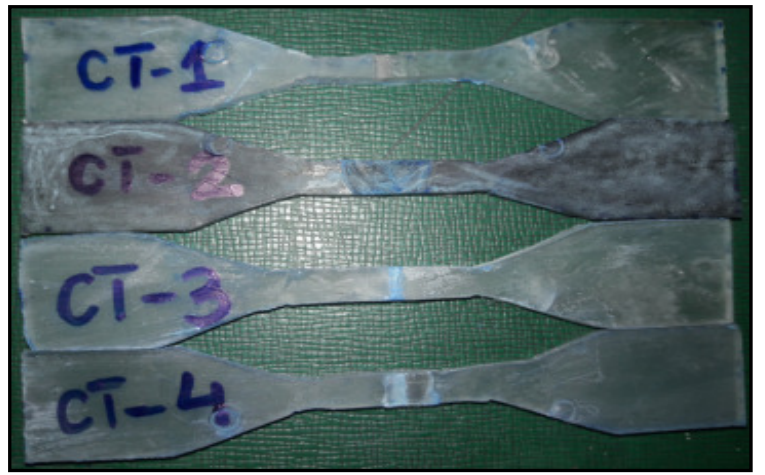

Fig. 17: Confirmation Test Samples

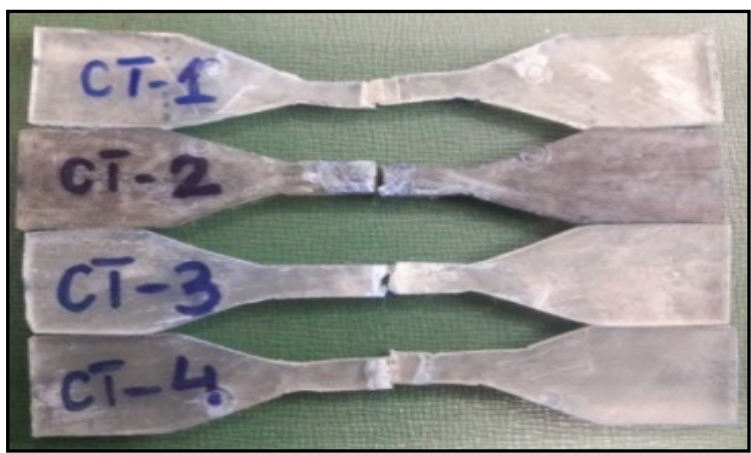

Fig. 18: Samples after Tensile Testing 


\begin{tabular}{|c|c|c|c|c|c|c|}
\hline \multicolumn{9}{|c|}{ Table 10: Confirmation Samples Test Results } \\
\hline RUN & $\begin{array}{c}\text { TRAVERSE } \\
\text { SPEED } \\
\end{array}$ & $\begin{array}{c}\text { ROTATIONAL } \\
\text { SPEED } \\
(\mathrm{mm} / \mathrm{min})\end{array}$ & RPM $)$ & TOOL GEOMETRY & \multicolumn{3}{|c|}{ UTS (units) } \\
\cline { 5 - 7 } & 14 & 1700 & Simple cylindrical conical & 53.169 & 51.299 & 3.6 \\
\hline 1 & 35 & 950 & Threaded cylindrical & 38.658 & 37.138 & 4.09 \\
\hline 3 & 35 & 950 & Threaded conical & 37.857 & 36.946 & 2.46 \\
\hline 4 & 35 & 950 & Threaded cylindrical conical & 27.928 & 26.269 & 1.65 \\
\hline
\end{tabular}

\section{SUMMARY AND CONCLUSIONS}

Friction Stir Welding (FSW) being a solid-state welding technique have its advantages (no heat affected zone, no change in the properties of base metals, possibility of joining dissimilar metals etc) over the fusion welding processes like Electric Arc welding and Gas Welding. Keeping this aspect in view a research work, presented in this paper, carried out the FSW of Polycarbonate sheets having butt joint configuration while optimizing the values of three important parameters: rotational speed, traversing speed and tool geometry (four types in total); used in combination with each other. The objective of this research was to use that combination of the above mentioned three parameters which resulted in maximizing the tensile strength of the welded joints. To minimize the number of possible combinations of the three different parameters while maximizing the tensile strength of the welded joints a central composite rotatable design was used in combination with a mathematical model developed by RSM. Analysis of Variance (ANOVA) was further utilized to check the suitability of the model and significance of the process parameters. To elaborate and signify the justification of this research work the effects of variations in rotational speed, traversing speed and all four tool geometries on the tensile strength of the welded joints were plotted on 3D graphs (Figs. 11, 12, 13 and 14). It was observed in all the 3D graphs that in case of all four tool geometries the simultaneous increase in both traversing and rotational speeds depicted that the tensile strength initially showed an increasing trend but after certain limit a decreasing trend was witnessed with further simultaneous increase in the values of both the parameters. The final results showed that the ultimate tensile strength of 51.299 MPa was achieved at the traversing speed of $14 \mathrm{~mm} / \mathrm{min}$, rotational speed of 1700 RPM and with simple cylindrical conical tool geometry.

\section{ACKNOWLEDGEMENT}

The authors hereby acknowledge the support and facilitation of the Mechanical Engineering Department at Wah Engineering College in general and Chairperson of the Department in particular.

\section{REFERENCES}

[1] Thomas W. M., Nicholas E. D., Needham J. C., Murch M. G., Temple-Smith P., Dawes C. J., "Friction stir butt welding", G.B. Patent 9125978.8, UK, 1991.

[2] Dashatan S.H., Azdast T., Ahmadi S.R., Bagheri A, "Friction stir spot welding of dissimilar polymethyl methacrylate and acrylonitrile butadiene styrene sheets", Materials and Design, Vol. 45, pp. 135-141, 2013.

[3] Yousefpour A., Hojatti M., Jean-Pierre I., "Fusion bonding/Welding of Thermoplastic composites", Journal of Thermoplastic Composite Materials, Vol. 17, Canada, 2004.

[4] Kah P., Suoranta R., Martikainen J., "Joining of Sheet Metals Using Different Welding Processes", Proceedings of 16th International Conference Mechanika, Kaunas, Lithuania, 2011.

[5] Matlack M.P., Burton K.A., "Friction stir welding tool cleaning method", Patent N0.2 US7641739B2, United States, 2010.

[6] Reynolds A.P., TangW., Gnaupel-Herold, T., Prask H., "Structure, properties, and residual stress of 304L stainless steel friction stir welds", Scripta Materialia, Vol. 48, pp. 1289-1294, 2003. 
[7] Mishra R.S., Ma Z.Y., "Friction stir welding and processing," Materials Science and Engineering: R: Reports, Vol. 50, No. 1-2, pp. 1-78, 2005.

[8] Scialpi A., Troughton M., Andrews S., De Filippis L.A.C., "In-line reciprocating friction stir welding of plastics', Joining Plastics/FFügen. Von Kunststoffen, Magazine, No. 1, pp. 42-51, 2007.

[9] Eslami S., Tavares P.J., Moreira P.M.G.P., "Friction stir welding tooling for polymers: review and prospects", International Journal of Advanced Manufacturing Technology, Vol. 89, pp. 1677-1690, 2017.

[10] Mehta K. P., Badheka V. J., "Influence of tool design and process parameters on dissimilar friction stir welding of copper to AA6061-T651 joints", International Journal of Advanced Manufacturing Technology, Vol. 80, No. 9-12, pp. 2073-2082, 2015.

[11] Derazkola H.A., Khodabakhshi F., Simchi A., "Friction-stir lap-joining of aluminiummagnesium/poly-methyl-methacrylate hybrid structures: thermo-mechanical modelling and experimental feasibility study", Science and Technology of Welding and Joining, Vol. 23, No.1, pp. 35-49, 2018.

[12] Rane A. J., Yadav M. S., "Effect of Friction Stir Welding Process on Mechanical And Thermal Behavior Of Dissimilar Material," International Journal of Engineering Sciences and Research Technology, Vol. 7, No.4, April 2018.

[13] Oyedemi K., McGrath P.., Lombard H., Varbai, B., "A Comparative Study of ToolPin Profile on Process Response of Friction Stir Welding of AA6082-T6 Aluminium Alloy, Periodica Polytechnica Mechanical Engineering”, Vol. 61, No. 4, pp. 296-302, 2017.

[14] Huanga Y., Meng X., Wang Y., Xie Y., Zhou L., "Joining of aluminum alloy and polymer via friction stir lap welding", Journal of Materials Processing Technology, Vol. 257, pp. 148-154, 2018.

[15] Panaskar N., Terkar R., "Study of Joining Different Types of Polymers by Friction Stir Welding”, In Mandal D.K., Syan C.S. (Eds.):
CAD/CAM, Robotics and Factories of Future, Lecture Notes in Mechanical Engineering, Springer, New Delhi. 2016.

[16] Sahu S. K., Mishra D., Mahto R.P., SharmaV.M., Pal S.K., Pal K., Banerjee S., Dash P., "Friction stir welding of polypropylene sheet", Engineering Science and Technology - An International Journal, Vol. 21, No.2, pp. 245-254 2018.

[17] Gao J., Shen Y., Xu H., "Investigations for the mechanical,macro-, and microstructural analyses of dissimilar submerged friction stir welding of acrylonitrile butadienestyrene and polycarbonate sheets, Proceedings of the Institution of Mechanical Engineers, Part B: Journal of Engineering Manufacture, Vol. 230, No.7, pp. 1213-1220, 2015.

[18] Sadeghian N., Givi M.K.B., "Experimental optimization of the mechanical properties of friction stir welded Acrylonitrile Butadiene Styrene sheets," Materials and Design, Vol. 67, pp. 145-153, 2015.

[19] Lambiase F., Paoletti A., Di Ilio A., "Mechanical behaviour of friction stir spot welds of polycarbonate sheets, International Journal of Advanced Manufacturing Technology," Vol. 80, pp 301-314, 2015.

[20] Mostafapour A.., Azarsa, E., "A study on the role of processing parameters in joining polyethylene sheets via heat assisted friction stir welding: Investigating microstructure, tensile and flexural properties, International Journal of the Physical Sciences, Vol. 7, No. 4, pp. 647 - 654, 2012.

[21] Astarita A., Boccarusso L., Carrino L., Durante M., Minutolo C., Memola F.., Squillace A., "Study of the Joining of Polycarbonate Panels in Butt Joint Configuration Through Friction Stir Welding", Proceedings of the 21st International ESAFORM Conference on Material Forming, Italy, 2018.

[22] Hajideh M. R., Shapurgan O., Ramzani N. M., Nejad E. H., "Friction Stir Welding of Dissimilar Poly Methyl Methacrylate and Polycarbonate Sheets, Journal of Modern Processes in Manufacturing and Production, Vol. 6, No. 4, 2017. 
[23] Hasanzadeh R., Azdast T., Doniavi A., Babazadeh S., Lee R. E., Daryadel M., Shishavan S. M., "Welding Properties of Polymeric Nano composite Parts Containing Alumina Nanoparticles in Friction Stir Welding Process", IJE Transactions A: Basics, Vol. 30, No. 1, pp. 143-151, 2017.

[24] Kim, W-K., Goo, B-C., Won S-T., "Optimal Design of Friction Stir Welding Process to Improve Tensile Force of the Joint of A6005 Extrusion", Materials and Manufacturing Processes, Vol. 25, No.7, pp. 637-643, 2010.

[25] Palanivel R., Mathews P. K., "Prediction and optimization of process parameter of friction stir welded AA5083- H111 aluminum alloy using response surface methodology", Journal of Central South Univesity, Vol. 19, pp. 1-8, 2012.

[26] Dhancholia D.D., Sharma A., Charit V., "Optimisation of Friction Stir Welding Parameters for AA6061 and AA 7039 Aluminium Alloys by Response Surface Methodology (RSM)", International Journal of Advanced Mechanical Engineering, Vol. 4, No. 5, pp. 565-571, 2014.

[27] Amirizad M., Kokabi A. H., Gharacheh M .A., Sarrafi R., Shalchi B., Azizieh M., "Evaluation of microstructure and mechanical properties in friction stir welded A $356+15 \%$ SiC p cast composite", Materials Letters, Vol. 60, No. 4, pp. 565-568, 2006.

[28] Payganeh G. H., Arab Mostafa N. B., Asl Y.D., Ghasemi F. A., Boroujeni M. S., "Effects of friction stir welding process parameters on appearance and strength of polypropylene composite welds", International Journal of the Physical Sciences, Vol. 6, No. 19, pp. 4595-4601, 2011.

[29] Panneerselvam K., Lenin K., "Joining of Nylon 6 plate by friction stir welding process using threaded pin profile", Materials and Design", Vol. 302-307, 2014.

[30] Eslami S., Ramos T., Tavares P.J., Moreira P.M.G.P., "Shoulder design developments for FSW lap joints of dissimilar polymers, Journal of Manufacturing Processes, Vol. 20 pp. 15-23, 2015.
[31] Zafar A., Awang M., Khan R. S., "Friction Stir Welding of Polymers: An overview, In Awang M. (Eds.), Proceedings of the 2nd International Conference on Mechanical, Manufacturing and Process Plant Engineering, Lecture Notes in Mechanical Engineering," Portugal, 2017.

[32] Bilici M.K., Yükler A.İ., "Influence of tool geometry and process parameters on macrostructure and static strength in friction stir spot welded polyethylene sheets", Materials and Design, Vol. 33, pp.145-152, 2012.

[33] Prakash P., Jha S.K., Lal, S.P., "Effect of Tool-Pin Profile on Weld Zone and Mechanical Properties in Friction Stir Welding of Aluminium Alloy", Pertanika Journal of Science and Technology, Vol. 26, No.2, pp. 853 - 862, 2018. 